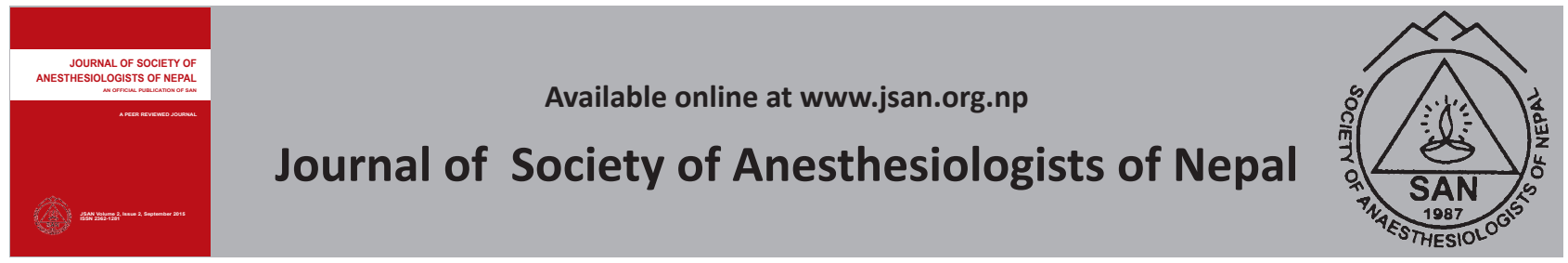

Original Article

\title{
Ketamine as an alternative to midazolam co-induction to propofol: a comparative study
}

Rupesh Kumar Yadav ${ }^{*}$, Gautam Ratna Bajracharya ${ }^{\ddagger}$, Jeju Nath Pokharel ${ }^{\epsilon}$

${ }^{\sharp}$ Civil Service Hospital, Min Bhawan, Kathmandu, Nepal

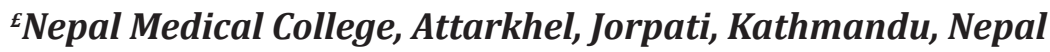

${ }^{\epsilon}$ Shahid Gangalal National Heart Center, Bansbari, Kathmandu, Nepal

\author{
ARTICLE I NFO \\ Article History \\ Received 11.07.2015 \\ Accepted 19.08. 2015 \\ Published 10.09.2015 \\ (C) Authors retain copyright \\ and grant the journal right \\ of first publication with the \\ work simultaneously licensed \\ under a Creative Commons \\ Attribution License that allows \\ others to share the work with \\ an acknowledgement of the \\ work's authorship and initial \\ publication in this journal.
}

\begin{abstract}
Background: Induction of anesthesia with propofol is known to produce systemic hypotension. Co-induction adds a small dose of other anesthetics to reduce the dose of induction agent to decrease hemodynamic disturbances. The aim of the study was to compare hemodynamic changes associated with Midazolam and ketamine as a coinduction agent with Propofol and to compare induction dose of Propofol following the co-induction.

Methods: Fifty adult patients undergoing elective surgery to be performed under general anesthesia were randomized to receive $0.3 \mathrm{mg} / \mathrm{kg}$ of Ketamine or $0.03 \mathrm{mg} /$ $\mathrm{kg}$ of Midazolam intravenously as co-induction agent. A minute after administration of co-induction agent, anesthesia was induced with Propofol $40 \mathrm{mg}$ bolus then $10 \mathrm{mg}$ every 10 seconds until the loss of verbal response. The hemodynamic response at 0 , 1, 2, 5 minutes respectively and the induction dose of Propofol were noted.

Results: The mean arterial pressure heart rates were significantly lower at 1, 2 and 5 minutes in midazolam group. However, mean arterial pressure and heart were within the physiological range in both the groups. Propofol dose requirement for induction between the two groups was similar $(p>0.05)$ but co-induction significantly decreased the induction dose of Propofol as compared to standard recommended dose for induction.

Conclusion: Our study showed that hemodynamic variables were maintained within the physiological range with midazolam and ketamine co-induction. However, lesser degree of decrease in mean arterial pressure was seen with ketamine but the heart rate was higher. A similar reduction of induction dose of propofol was achieved with both the drugs.
\end{abstract}

Keywords: Combined anesthetic; Ketamine; Midazolam; Propofol.

How to cite this article: Yadav RK, Bajracharya GR, Pokharel JN. Ketamine as an alternative to midazolam co-induction to propofol: a comparative study. JSAN 2015;2:62-66.

\footnotetext{
Corresponding author: Rupesh Kumar Yadav, MD

Registrar Anesthesiology,

Civil Service Hospital, Min Bhawan,

Kathmandu, Nepal, Telephone: +9779841484121

Email: rupesh905@hotmail.com
} 


\section{Introduction}

The term co-induction has been used to describe the practice of administrating a small dose of sedative or other anesthetic agents to reduce the dose of induction agent. ${ }^{1}$ The main objective of this technique is to improve the ratio of desired versus adverse effects and to reduce the cost of expensive drugs such as Propofol.

Propofol is an intravenous sedative hypnotic which produces unconsciousness within 30 seconds after intravenous injection. The more rapid return of consciousness with minimal residual central nervous affects is one of the most important advantages of Propofol. The induction dose of Propofol is 1.5 to $2.5 \mathrm{mg} /$ $\mathrm{kg}$ intravenous with blood level of 2 to $6 \mathrm{mg} / \mathrm{ml}$. It also depends on the associated medications and the patient's age. ${ }^{2}$ It produces the decrease in systemic blood pressure with bradycardia or no change in heart rate. ${ }^{3}$

Ketamine is a phencyclidine derivative that produces dissociative anesthesia. Systemic and pulmonary arterial blood pressure, heart rate, cardiac output, cardiac work and myocardial oxygen requirement are increased after intravenous administration. ${ }^{4}$

Midazolam is a benzodiazepine with potent amnesic effect than sedation. Induction dose causes greater decrease in systemic blood pressure and increase in heart rate. Most significant side effect of Midazolam is depression of ventilation caused by decrease in the hypoxic drive. ${ }^{5}$

Since Midazolam is commonly used as a co-induction agent with Propofol, thinking of an alternative choice, the prospective study was designed to compare Ketamine with Midazolam as a co-induction agent with Propofol.

\section{Methods}

This was a prospective, randomized, double-blind and interventional study conducted at Bir Hospital, Kathmandu, Nepal. Fifty patients of age 18 to 65 years of ASA I and ASA II, undergoing elective surgery to be performed under general Anesthesia were randomly selected and divided into two groups. Patients in group $\mathrm{K}$ received 0.3 $\mathrm{mg} / \mathrm{kg}$ of Ketamine and group $\mathrm{M}$ received $0.03 \mathrm{mg} / \mathrm{kg}$ of Midazolam intravenously before induction agent propofol was administered.

\section{Anesthetic Technique}

A day prior preoperative evaluation of the patients was done and the Consent was taken from the patients for the enrollment into the study. No premedications were given.

Patients enrolled into the study were randomly divided into one of the two groups by lottery method-

Group M scheduled to receive Midazolam $0.03 \mathrm{mg} / \mathrm{kg}$ body weight before induction with propofol
Group K scheduled to receive Ketamine $0.3 \mathrm{mg} / \mathrm{kg}$ body weight before induction with propofol.

On the day of surgery, in the operation theatre, peripheral venous access was secured and monitors for vital parameters (heart rate, Electrocardiogram, Blood pressure, pulse oximeter) were attached. The co-induction agent was prepared in a $5 \mathrm{ml}$ syringe by another Anesthesiologist or Anesthetic assistant who did not take part in the study. Pethidine $0.5 \mathrm{mg} / \mathrm{kg}$ and the co-induction agent were given intravenously. The patient in group $M$ received $0.03 \mathrm{mg} /$ $\mathrm{kg}$ of Midazolam and the patient in group $\mathrm{K}$ received 0.3 $\mathrm{mg} / \mathrm{kg}$ of Ketamine. One min after the co-induction agent patients were induced with Propofol $40 \mathrm{mg}$ bolus then 10 mg every 10seconds until the loss of eye lash reflex and verbal response. Face mask was applied tightly at this point and with any response to the placement of mask additional bolus of Propofol 10mg was given. The study was completed at this point before the maintenance of anesthesia starts and further anesthetic technique did not influence the study.

Anaesthesia was continued with the standard practice, with Vecuronium $0.1 \mathrm{mg} / \mathrm{kg}$ as muscle relaxant intubated with cuffed orotracheal tube of proper size. Anesthesia was maintained with Isofluorane/Halothane in oxygen, Vecuronium for muscle relaxation and intermittent positive pressure ventillation. At the end of the surgery patients were reversed with Neostigmine $0.05 \mathrm{mg} / \mathrm{kg}$ and Atropine $0.025 \mathrm{mg} / \mathrm{kg}$. Patients were shifted to post anesthetic care unit after extubation of trachea.

Demographic variables were noted. Heart rate (HR) and Mean Arterial Pressure (MAP) were recorded preoperatively, 1, 2 and 5 minutes.

\section{Statistical analysis}

Sample size was calculated considering type I error of 0.05 and power 0.80 , assuming a percentage change in mean of $20 \%$ and percentage coefficient of variation of $30 \%$ in dose of propofol between two groups, the calculated sample size was a total of 50 patients divided into two groups of 25 patients each. Statistical test: student's T-test and $X^{2}$ tests were applied for the comparision and $P$ value $<0.05$ was considered as significant.

\section{Results}

A total of 50 patients ( $n=25$ in each group) who met the inclusion criteria were included in this study. The patients where between age group of 20 years to 61 years and weight of $40 \mathrm{~kg}$ to $80 \mathrm{~kg}$ and had ASA physical status 1.

As there were no significant differences in age, sex, weight and ASA physical status of patients, between the two groups, both of the groups were comparable. 
JSAN 2015; 2 (2)

Table 1: Demographic distribution

\begin{tabular}{llll}
\hline Group & Midzolam & Ketamine & P value \\
\hline $\begin{array}{l}\text { Age in years } \\
\text { ( mean } \pm\end{array}$ & $36.48 \pm 9.33$ & $37.48 \pm 11.06$ & 0.731 \\
SD ) & & & \\
Sex ( M/F) & $4 / 21$ & $5 / 20$ & 1.0 \\
ASA I & 25 & 25 & 1.0 \\
Weight in kg & $55.92 \pm 12.27$ & $55.76 \pm 10.001$ & 0.96 \\
\hline
\end{tabular}

There was significant decrease in heart rate in the Midazolam group after induction of anesthesia at 1, 2, and 5 minutes. But, it initially increased from baseline in the ketamine group at one and two minutes. Heart rate in the ketamine group remained significantly higher at all times of observation. (Table 2)

Table 2: Heart rate in beats/ minutes

\begin{tabular}{llll}
\hline Groups & Midazolam & Ketamine & P value \\
\hline $\begin{array}{l}\text { Baseline ( Mean } \pm \\
\text { SD ) }\end{array}$ & $\begin{array}{l}87.48 \pm \\
16.008\end{array}$ & $\begin{array}{l}87.92 \pm \\
19.40\end{array}$ & 0.93 \\
& & & \\
& & & \\
1 minute after co- & $76.84 \pm$ & $91.68 \pm$ & 0.001 \\
inducton (Mean \pm & 15.98 & 13.93 & \\
SD ) & & & \\
2 minute after co- & $74.80 \pm$ & $89.48 \pm$ & 0.000 \\
$\begin{array}{l}\text { induction (Mean } \pm \\
\text { SD ) }\end{array}$ & 13.48 & 13.98 & \\
5 minute after co- & $75.56 \pm$ & $84.88 \pm$ & 0.025 \\
induction (Mean \pm & 12.53 & 15.73 & \\
SD ) & & & \\
\hline
\end{tabular}

The baseline Mean arterial blood pressure (MAP) was measured and also recorded at 1, 2 and 5 minutes after induction. There was a significant decrease in MAP at 1, 2 and 5 minutes after induction of anesthesia in the Midazolam group. (Table 3)

Table 3: Mean arterial pressure in $\mathrm{mm}$ of $\mathrm{Hg}$

\begin{tabular}{llll}
\hline Groups & Midazolam & Ketamine & P value \\
\hline Base line MAP & $94.68 \pm 13.06$ & $93.04 \pm 12.12$ & 0.648 \\
$\begin{array}{l}\text { MAP at 1 } \\
\text { minute }\end{array}$ & $82.40 \pm 12.92$ & $89.28 \pm 8.93$ & 0.034 \\
$\begin{array}{l}\text { MAP at 2 } \\
\text { minute }\end{array}$ & $75.40 \pm 10.41$ & $83.32 \pm 9.23$ & 0.007 \\
$\begin{array}{l}\text { MAP at 5 } \\
\text { minute }\end{array}$ & $78.12 \pm 10.146$ & $85.04 \pm 9.145$ & 0.015
\end{tabular}

For induction of Anesthesia $40 \mathrm{mg}$ of Propofol was given as a bolus dose in both of the groups irrespective of weight and age of the patient followed by additional dose of $10 \mathrm{mg}$ Propofol every 10 seconds until there was loss of verbal response. The induction dose of Propofol required in the two groups did not differ significantly and is shown in the following table 4.

64
Table 4: Total induction dose of Propofol (in mg)

\begin{tabular}{llll}
\hline Group & Midazolam & Ketamine & P value \\
\hline Total induction & $55.60 \pm$ & $54.80 \pm$ & 0.867 \\
dose of Propofol & 17.81 & 15.84 & \\
(Mean \pm SD) & & & \\
\hline
\end{tabular}

\section{Discussion}

The development of intravenous agents has been an important component of anesthetic management. Rapid emergence from anesthesia and post operative recovery of cognitive function as well as hemodynamic stability is important requirement of modern anesthesia. Propofol meets the former two requirements but is known to produce hemodynamic disturbances. We aimed to study whether adding a small dose of midazolam or ketamine would give better blood pressure and heart rate control or not.

In our study 50 patients undergoing routine surgical procedures under general anesthesia were selected and randomly divided into two groups as group $\mathrm{M}$ - Midazolam and K-Ketamine group of 25 patients each. The two groups were comparable in terms of age, and base line hemodynamics.

All patients received Pethidine $0.5 \mathrm{mg} / \mathrm{kg}$ as an analgesic. Then patients in group $M$ received $0.03 \mathrm{mg} / \mathrm{kg}$ of Midazolam and patients in group $\mathrm{K}$ received $0.3 \mathrm{mg} / \mathrm{kg}$ of Ketamine as a co-induction agent. One minute after co-induction the patients were given $40 \mathrm{mg}$ of Propofol irrespective of weight. $10 \mathrm{mg}$ bolus of Propofol was added every 10 seconds according to the loss of verbal response or any movement with face mask ventilation. This dose of Propofol was based on our pilot study. We had done a pilot study with $30 \mathrm{mg}$ bolus of Propofol as used by $U$ Srivastava ${ }^{6}$ in the study done in 2006 . But we found the dose to be inadequate, so we increased the dose to 40 $\mathrm{mg}$ in our present study. This higher dose requirement for induction in our study may be due to the use of Pethidine in our study while they used Fentanyl (one microgram per $\mathrm{kg}$ ). The hemodynamics was observed at 1, 2, 5 minutes respectively and this was the end point of the study before maintenance of anesthesia and endotracheal intubation was performed. We observed the hemodynamics at these intervals because we used non invasive blood pressure monitoring. A more frequent noninvasive blood pressure monitoring interval may lead to less reliable reading of blood pressure.

After delivering intravenous drugs for general anesthesia to the patients due to their vasodilator effects they tend to decrease the blood pressure and mean arterial pressure. The extent of the fall depends upon the dose and adjuvant drugs used. The result of our study showed that there was significantly lower in Heart rate in Midazolam group as compared to Ketamine group at all times of observations that is 1,2 , and 5 minutes following co-induction ( $p$ value $<0.05$ ). The highest fall in Heart rate was noticed at 2 minutes in Midazolam group as compared with Ketamine. 
In a similar study done by Sirvastava et $\mathrm{al}^{6}$ in 2006 among 68 ASA I and II patients undergoing elective surgery under general anesthesia they found that there was a fall in Heart rate and MAP in all groups but there was a significant fall in Heart rate and mean arterial blood pressure in saline group compared to Ketamine group where as there was no significant difference in Heart rate and mean arterial blood pressure between Midazolam and saline group. They had used a similar co-induction dose of Midazolam and Ketamine as in our study but they had induced with a lower dose of Propofol (30 mg in their study vs $40 \mathrm{mg}$ in our study). All the patients in their group received Fentanyl but in our study we used Pethidine. The induction dose was given 1 minute after co-induction in our study but they induced 2 minutes following co-induction. Their study did not compare between Midazolam and Ketamine group as compared to our study. Our study showed that there was a significant decrease in blood pressure and heart rate in the midazolam group but it remained within the physiological range.

Ong and Osborne ${ }^{7}$ in 2001 studied the effect of Ketamine co-induction to Propofol on Propofol induction dose and hemodynamics. They included 40 ASA I and II for third molar tooth extraction in their study. They found a significant reduction in Heart rate and mean arterial blood pressure in saline group compared to Ketamine group at the time of induction (that is 2 minute after co-induction). They did not find any significant difference between the two groups in terms of Heart rate and mean arterial blood pressure at other times of observation. In our study we found significant difference in Heart rate and mean arterial blood pressure at all time of observation between the two groups with higher heart rate and MAP with the use of Ketamine. They have compared Ketamine with saline group where as we have compared Ketamine and Midazolam in our study. We have used similar dose of Ketamine as in their study but they have given the induction dose of Propofol 80 seconds following co-induction. The dose of Propofol used in their study was $300 \mathrm{ml} / \mathrm{hr}$ but in our study we have used $40 \mathrm{mg}$ bolus dose of Propofol.

Salah Mostafa Asida ${ }^{8}$ in the year 2004 did a study to compare the effect of Midazolam co-induction and propofol predosing on the induction dose requirements of propofol. 150 patients over 65 years undergoing urological surgeries were included. Their study did not find any significant difference in Heart rate and mean arterial blood pressure following induction in Midazolam group compared to saline group. They compared Midazolam with saline group but our study compared Ketamine with Midazolam group. In our study we found Midazolam significantly decreased Heart rate and mean arterial blood pressure compared to Ketamine.

Propofol is a choice for intravenous induction of anesthesia because of its faster onset and quick recovery. The recommended induction dose of Propofol is 1.0 to $2.5 \mathrm{mg} /$ $\mathrm{kg}^{2}$
The average weight of the patients in our study was 55.92 $\mathrm{kg}$ in Midazolam group and $55.76 \mathrm{~kg}$ in Ketamine group. If we use propofol in a recommended dose of $2 \mathrm{mg} / \mathrm{kg}$, they would require $111.84 \mathrm{mg}$ of Propofol in Midazolam group and $111.52 \mathrm{mg}$ in Ketamine group. However in our study we found that in Midazolam group, the patients required $55.60 \pm 17.81 \mathrm{mg}$ of Propofol for induction and in Ketamine group, they required $54.80 \pm 15.84 \mathrm{mg}$ of Propofol. Though there was no significant difference in the induction dose of Propofol between the two groups ( $p$ value 0.867 ), the induction dose in both the groups was less than the recommended standard dose. So our study shows that both the co-induction agents were effective in reducing the dose of Propofol.

Dose reduction of Propofol following Midazolam coinduction is probably due to synergistic interaction between both of the drugs. Synergism has been reported between agents with known functional link in the central nervous system with Midazolam and Propofol activity on a same receptor, the GABA receptor. ${ }^{6}$

Though both agents act in different receptors, Ketamine acts by antagonism of NMDA receptor and Propofol acts on GABA receptor. Reduction dose of Propofol requirement following Ketamine is explained by an additive sedation effect of both of the drugs. ${ }^{9}$

Co-induction reduces the dose of induction agent required to achieve hypnosis and any forms of premedication is likely to have similar effect.Error! Bookmark not defined. ${ }^{10}$

Propofol is known to cause significant reduction in MAP and heart rate. As co-induction was found to decrease the dose requirement of Propofol for induction, the hemodynamic stability seen can also be due to the lower dose of Propofol used for induction of anesthesia.

There were few limitations in our study. We did not compare the drugs with a placebo group. We could not use Fentanyl in our study due to unavailability of the drug. Since Fentanyl provides a synergistic effect with Propofol, there might have been even better results for dose reduction of Propofol. We did not monitor the hemodynamics using invasive blood pressure monitor. We did not study the side effects of the study drugs like postoperative nausea and vomiting, hallucinations, post operative recovery, etc. Considering analgesic action of ketamine, we could have studied the postoperative analgesic requirement in the two groups.

\section{Conclusion}

Propofol is a commonly used intravenous induction agent because of its fast onset and quick recovery but a well known side effect is unstable hemodynamics. Co-induction with ketamine was associated with lesser change in mean arterial pressure and heart rate. However, the decrease in the heart rater and mean arterial pressure was also within the physiological range. A lesser degree of decrease in mean arterial pressure was seen with ketamine but the 
heart rate was higher. Co-induction significantly decreased the induction dose of Propofol as compared to standard recommended dose but, the dose reduction of Propofol for induction of anesthesia was not significant between the groups.

\section{References}

1. Anderson L, Robb H. A comparison of midazolam co-induction with propofol predosing for induction of anaesthesia. Anaesthesia 1998;53:1117-20.

2. Bryson HM, Fulton BR, Faulds D. Propofol: An update of its use in anesthesia and conscious sedation. Drugs 1995;50:513-59.

3. Cressy DM, Claydon P, Bhaskaran NC, Reilly CS. Effect of Midazolam pretreatment on induction dose requirement of Propofol in combination with Fentanyl in younger and older adults. Anesth 2001;56:108-13.

4. Tweed WA, Minuck MS, Mymin D. Circulatory response to Ketamine anesthesia. Anesthesiology 1972;37:613-9.

5. Collins LM, Conney CM, Fitzpatrick G. Propofol induction characteristics after Fentanyl or Midazolam and Fentanyl. $\mathrm{Br} \mathrm{J}$ Anesth 1997;79:676-7.

6. Srivastava U, Sharma N, Kumar A, Saxena S. Small dose of Propofol or Ketamine as an alternative to Midazolam co induction to Propofol. Indian J Anaesth 2006;50:112-4.

7. Ong EL, Osborne GA. Ketamine for co-induction of anaesthesia in oral surgery. Ambulatory Surg 2001;9:131-5.

8. Asida SM. Midazolam co-induction in the elderly. El-Minia Med Bull 2004;15:300-7.

9. Hui TW, Short TG, Hong W, Suen T, Gin T, Plummer J. Additive interactions between Propofol and Ketamine when used for Anaesthesia induction in female patients. Anesthisology 1995;82:641-48.

10. Adachi YU, Uchihashi Y, Wetanab K, Satoh T. Small dose Midazolam or Droperidol reduces the hypnotic dose of Propofol at the induction of Anaesthesia. Euro J Anaesthesiol 2000;17:126-31. 